\title{
Idiopathic Pulmonary Trunk Aneurysm in 74-Year-Old Patient
}

\section{Anetta Kowalczuk-Wieteska ${ }^{1 *}$, Bogusław Ryfiński ${ }^{1}$, Jan Głowacki ${ }^{2}$ and Marian Zembala ${ }^{1}$}

${ }^{1}$ Clinical Department of Cardiac Surgery, Transplantation, Surgery, Vascular and Endovascular SUM Silesian Center for Heart Diseases, Poland ${ }^{2}$ Laboratory of Computer Tomography and X-ray Laboratory Silesian Center for Heart Diseases

Pulmonary artery aneurysm is an enlargement of the pulmonary artery by more than $50 \%$ compared to its normal diameter. Pulmonary aneurysm is estimated at 1:14,000 cases of autopsy [1]. Congenital dilated pulmonary trunk diagnosed in 6 patients per 1000 patients diagnosed with other heart defect. The acquired pulmonary aneurysm is in a pulmonary hypertension in the course of a mitral stenosis; followed by lung cancer; tuberculosis aneurysm Rasmussen; syphilis or fungal infections; vascular inflammatory, such as disease-Hughes Stovina, Behcet's syndrome, Marfan syndrome [2]. In June 2016 was admitted 74-year-old to coronary artery bypass implantation.

During cardiological diagnostics in Czestochowa, when the patient was treated angioplasty with implantation an antimitotic stent to right coronary artery after during non-ST elevation myocardial infarction, the chest radiology scan highlighted enlargement left pulmonary hill. The patient was treated undergoing hypertension and paroxysmal atrial fibrillation so far. The patient did not complain of cough or hemoptysis. From the time of myocardial infarction was stable cardiac CCS class II and NYHA II. In a transthoracic echocardiography (TTE) anatomy of the right ventricle and pulmonary valve were normal, no pulmonary hypertension. A chest computed tomography (CT) scan the left pulmonary artery was $50 \mathrm{~mm}$ in diameter (Figure 1). Euro SCORE operative risk was high and reached 8 points ( 3 for age, 3 for LVEF $47 \%, 2$ for myocardial infarction $<90$ days) with a logistic score of 37. Optimal treatment of pulmonary arterial aneurysm has not been established. If pulmonary aneurysm is $>55 \mathrm{~mm}$, or a fold increase of $>5$ $\mathrm{mm}$ within six months, with thrombus in the aneurysm sack are their clinical symptoms or dissection is recommended surgery treatment [3-5]. On 30-06-2016 we have implanted two bypasses: LIMA >LAD and Ao >OM1. After opening the patient's chest we observed large aneurysm of pulmonary trunk. We backed out of surgery treatment this aneurysm because it was very thin wall, covered for normally size ascendant aorta. It was taken very aortic wall to aim was to doing nearest anastomosis. All heart was in solid, hard adhesions with pericardium. It make difficult for identification coronary arteries.

Anatomically pulmonary trunk aneurysm was passed on the left pulmonary artery. The right pulmonary artery was normal size. The

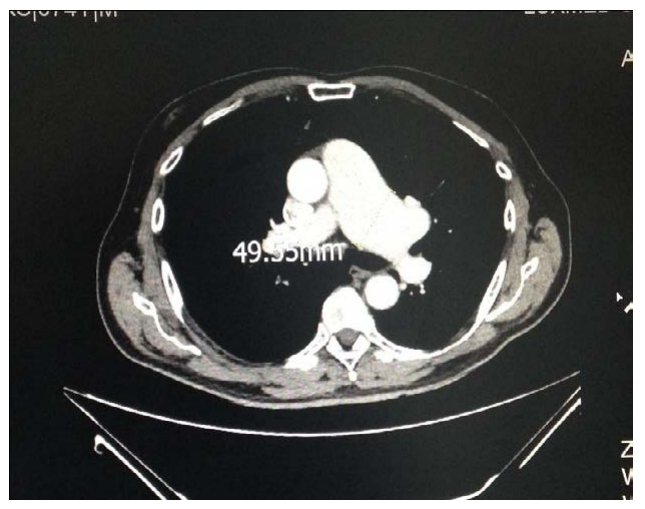

Figure 1: A chest computed tomography (CT) scan the left pulmonary artery. patient was extubated as planned, with good respiratory and circulatory function. Postoperative hospitalization time was not complicated. The patient was extubated as planned, with good respiratory and circulatory function. Follow-up examination supplementation was subsequently started. The patient underwent a standard process of in-hospital rehabilitation, and from the third post-operative day was able to walk down the hospital hallway. On the post-operative day, the patient was discharged in very good condition; the wound was healed by primary intention. On discharge, long-term antiplatelet therapy -clopidogrel, warfarin, atorvastatin, angiotensin converting enzyme, beta-blocker, and antidiuretic was recommended. Patient went home after 7 days from operation.

\section{References}

1. Puri D, Kaur HP, Brar R, Singh KP, Sahoo M, et al. (2011) Ruptured pulmonary artery aneurysm: a surgical emergency. Asian Cardiovasc Thorac Ann 19: 436-439.

2. Vural AH, Turk T, Ata Y, Goncu T, Ozyazicioglu A (2007) Idiopathic asymptomatic main pulmonary artery aneurysm: surgery or conservative management? A case report. Heart Surg Forum 10: E273-E275.

3. Ferretti GR, Thony F, Link KM, Durand M, Wollschläger K, et al. (1996) False aneurysm of the pulmonary artery induced by a Swan-Ganz catheter: clinical presentation and radiologic management. AJR Am J Roentgenol 167: 941-945.

4. Wilson N, McLeod K, Hallworth D (2000) Images in cardiology: exclusion of a pulmonary artery aneurysm using a covered stent. Heart.

5. Breymann T, Blanz U, Wojtalik MA, Daenen W, Hetzer R, et al. (2009) European Contegra multicentre study: 7-year results after 165 valved bovine jugular vein graft implantations. Thorac Cardiovasc Surg 57: 257-269.
*Corresponding author: Anetta Kowalczuk-Wieteska, MD, PhD, Clinical Department of Cardiac Surgery, Transplantation, Surgery, Vascular and Endovascular SUM Silesian Center for Heart Diseases, Poland, Tel: +48 323733700; E-mail: kowaletta@onet.eu

Received February 10, 2017; Accepted March 01, 2017; Published March 07 2017

Citation: Kowalczuk-Wieteska A, Ryfiński B, Głowacki J, Zembala M (2017) Idiopathic Pulmonary Trunk Aneurysm in 74-Year-Old Patient. J Vasc Med Surg 5: 310. doi: 10.4172/2329-6925.1000310

Copyright: (c) 2017 Kowalczuk-Wieteska A, et al. This is an open-access article distributed under the terms of the Creative Commons Attribution License, which permits unrestricted use, distribution, and reproduction in any medium, provided the original author and source are credited. 